Research Article

\title{
Field Test and Simulation Analysis of Thermal Performance of Bamboo Steel Composite Wall in Different Climate Regions
}

\author{
Qifeng Shan $\mathbb{D}^{1},{ }^{1}$ Keting Tong, ${ }^{1}$ Xiaocun Zhang, ${ }^{1}$ and Yushun Li $\mathbb{D}^{2}$ \\ ${ }^{1}$ School of Civil and Environmental Engineering, Ningbo University, Ningbo 315211, China \\ ${ }^{2}$ School of Civil Engineering, Qingdao Agricultural University, Qingdao 266109, China \\ Correspondence should be addressed to Yushun Li; lys0451@163.com
}

Received 8 September 2020; Revised 27 September 2020; Accepted 30 September 2020; Published 14 October 2020

Academic Editor: Min-Juan He

Copyright (c) 2020 Qifeng Shan et al. This is an open access article distributed under the Creative Commons Attribution License, which permits unrestricted use, distribution, and reproduction in any medium, provided the original work is properly cited.

In this paper, a bamboo steel composite testing building was designed and built to study the thermal performance of a new proposed bamboo steel composite wall. The heat flux meter method was adopted in the field test to measure the heat transfer coefficient of the composite wall. The energy consumption of testing building was measured to verify the validity of the simulation model. Then, the simulation analysis was conducted to study the energy performance of the composite walls compared with reinforced concrete wall in different climate regions. The result showed that the measurement value of heat transfer coefficient matched well with the theoretical calculation value, and both values meet the requirement of the standard. The simulation result showed that the composite walls had better energy performance and had great potential utilization in residential buildings in different climate regions.

\section{Introduction}

With the development of the society, excessive resource consumption has become an important problem in developing economy and improving people's living standards. The resource consumption of building and building-related activities has a huge share in total resource consumption $[1,2]$. It is essential to promote renewable materials to replace non-renewable and heavily polluted building materials such as steel, concrete, and brick masonry.

Bamboo is one of the fastest growing renewable resources and the yearly output yield is higher compared with wood. Besides, bamboo has the advantages of high strengthto-weight ratio and good seismic resistant performance. It is a sustainable building material and can be competitive with traditional materials $[3,4]$.

To reduce the resource consumption, low-energy buildings have received widespread concerns. The main design of low-energy buildings is to improve a building's thermal performance [1]. Some studies showed that the bamboo exhibited good thermal performance: Shah et al. [5] reported that the engineered bamboo with high density had lower thermal conductivities than equivalent timber products. Takagi et al. [6] investigated the insulating properties of the PLA-bamboo fiber and found that the thermal conductivity of PLA-bamboo fiber is smaller than that of conventional composites.

Some researchers carried out the study on the thermal performance of bamboo composite walls: Xiang et al. [7] tested the thermal properties of compound bamboo wall in different moisture content. The study indicated that the thermal insulation performance of bamboo plywood was better than traditional building materials. Risnandar and Wonorahardjo [8] proposed a plastered-bamboo wall composed of bamboo as a frame and mortar as a frame cover. The proposed wall had better thermal properties than brick wall while the density of proposed wall was lower than brick wall. Wang et al. [9] studied the insulating properties of bamboo-based shear wall, which indicated the possible application of bamboo-based shear wall in light-frame building.

However, the bamboo structure members have lower bearing capacity than the steel members under the same dimensions $[10,11]$. Thus, the bamboo structure members 
strengthened by other materials such as steel bars $[12,13]$, fiber polymer [14], and FRP sheets or grid [15-18] were designed and investigated in recent years.

Bamboo steel composite members are a new kind of composite structure, which are made of bamboo plywood and cold-formed thin-walled steel. The bamboo steel composite members combine the advantages of light weight and high strength of bamboo plywood and steel, while the disadvantage of easy buckling of thin-walled steel is overcome. Recently, some researchers have proposed some bamboo steel composite components, such as bamboo steel composite columns [19], beams [20], and slabs [21, 22]. The researches had shown the cooperation of the two materials could effectively improve the mechanical performance of the composite members.

The authors proposed a new type of bamboo steel composite walls; these new walls can be fabricated in factory and quickly installed on-site. Relative research had shown that the composite walls had better bearing capacity and ductility compared with reinforced concrete wall [23]. However, the thermal performance of the proposed walls has not been studied. This paper is aimed at investigating the thermal performance of bamboo steel composite wall and its potential application in different climate regions. In this study, a testing building made of bamboo steel composite walls was built to test the thermal performance of the proposed wall. Then, the simulation was conducted to assess the energy performance of the composite walls compared with reinforced concrete wall in different climate regions.

\section{Project Overview}

As is shown in Figure 1, a bamboo steel composite building for field measurement was built in Ningbo, where is a typical city with hot summer and cold winter in China. All the members for the testing building including beams, plates, and columns were precast in the laboratory. The prefabricated members were transported to the destination for on-site installation. Thermal insulation and waterproof measures were taken for the testing building as common houses. This was the first truly new type of bamboo steel composite building which consisted of steel bamboo composite members and reinforced concrete floor. The singlestorey building covered an area of $24 \mathrm{~m}^{2}$ and the height of the building was $3 \mathrm{~m}$. The ratio of window area to wall area was 0.24 for the north wall and 0.31 for the south wall, respectively, while there were no windows in east and west walls. The windows adopted here were ordinary windows with $6 \mathrm{~mm}$ single glazing. The floor of the testing building was made of concrete with a thickness of $120 \mathrm{~mm}$.

2.1. Design of Wall. The bamboo steel composite walls structure is shown in Figure 2. The composite wall is composed of two bamboo plywoods with a thickness of $10 \mathrm{~mm}$ as cover panels and strengthened by several bamboo steel composite skeletons. The composite skeletons shown in Figure 3(a) are made of C-type steel which was sandwiched by two bamboo plywoods with a thickness of $20 \mathrm{~mm}$. The dimension $(h \times b \times c \times t)$ of C-type steel shown in Figure 3(b) is $100 \mathrm{~mm} \times 50 \mathrm{~mm} \times 20 \mathrm{~mm} \times 1 \mathrm{~mm}$. As is illustrated in Figure 1(b), the testing building belongs to frame structure. The walls of testing building are employed as building envelopes. Thus, the design of walls is mainly to satisfy the requirement of thermal performance. The cavity of wall is filled with mineral wool as insulation material. Several layers are covered on the outer surface of the wall including cement mortar and polystyrene board; the total thickness of the composite wall is $170 \mathrm{~mm}$. The construction of the composite wall is shown in Figure 4.

The east wall dimension of the testing building was $3.27 \mathrm{~m} \times 2.68 \mathrm{~m}$. Due to the difficulty in production and installation of the entire wall, the composite wall was divided into three pieces with the same size of $1.09 \mathrm{~m} \times 2.68 \mathrm{~m}$. The mechanical experiments of composite walls suggest that the suitable distance between composite skeletons varies from $250 \mathrm{~mm}$ to $400 \mathrm{~mm}$. Two composite skeletons should be employed in the edge of wall. The width of every wall is $1090 \mathrm{~mm}$; thus, two extra composite skeletons need to be added to strengthen the composite walls. The walls were evenly divided into three cavities by four skeletons and the center-to-center distance between skeletons is $333 \mathrm{~mm}$. Then, the three pieces of walls were spliced by thin steel sheet and bolts during the on-site installation. The composite walls were employed as building envelopes; thus, the connection between walls was designed to maintain their integrity. While the insulation performance of splice between walls was taken seriously, polystyrene board was entirely covered over the splice, steel sheet, and bolts to ensure thermal performance of composite walls (Figure 1(c)).

2.2. Manufacture of Wall. As described above, the manufacture of composite wall mainly includes 3 processes, i.e., the production of composite skeletons, the combination of two bamboo plywood cover panels with skeletons, and filling with insulation material in the cavity of walls. The production processes of the walls are illustrated in Figure 5 and the specific manufacture processes are as follows:

(1) Polish the interface between the C-type steel and bamboo plywood, and then wipe the polished steel and bamboo plywood with alcohol wipes to ensure that the bonding surface is clean (Figure 5(a)).

(2) Apply the pre-mixed structural adhesive evenly on the surface of the C-type steel. Fix the bamboo plywood and steel with fixtures to make sure that the two materials were bonded effectively. Besides, symmetrically place heavy objects on the bond surface to improve the quality of bond (Figure 5(b)).

(3) Fill three layers of mineral wool into the cavity of the C-type steel (Figure 5(c)), and then bond them with another bamboo plywood followed by the above steps (Figure 5(d)). Finally, the composite skeleton with insulation material is completed (Figure 5(e)).

(4) The skeletons are bonded on the bamboo plywood cover panels as designed and the adhesive procedure follows the steps above (Figure 5(f)). 

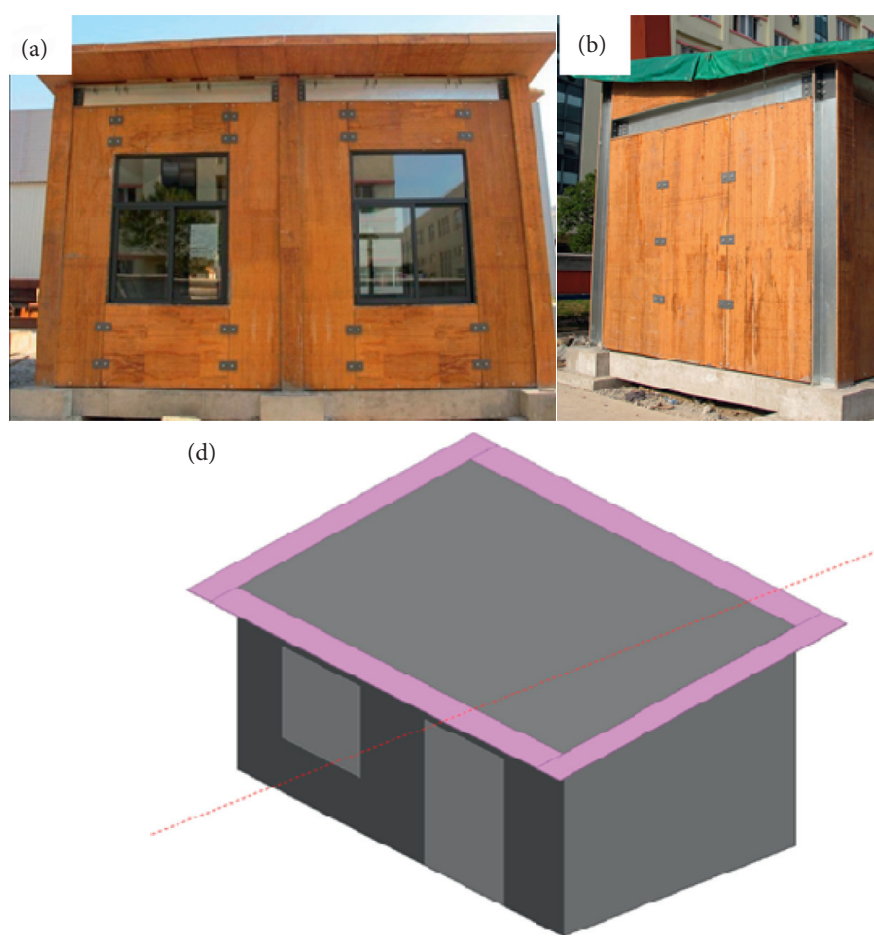

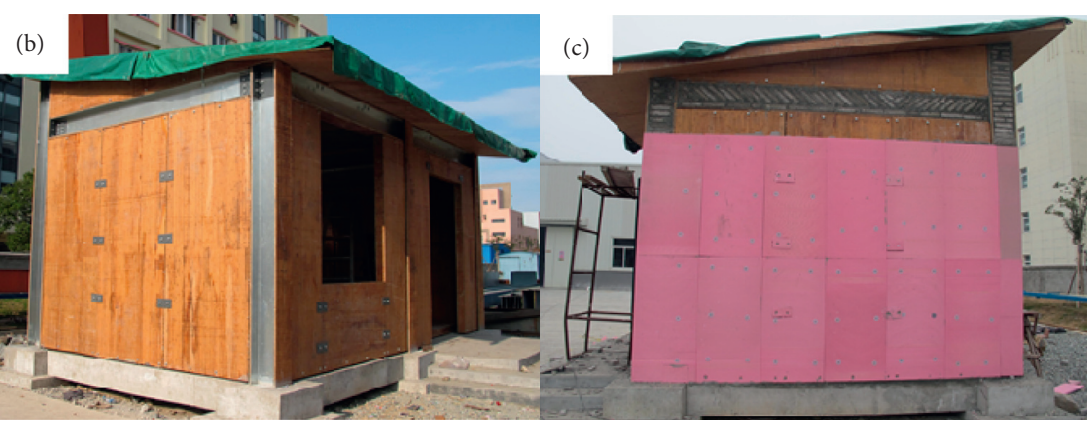

(e)

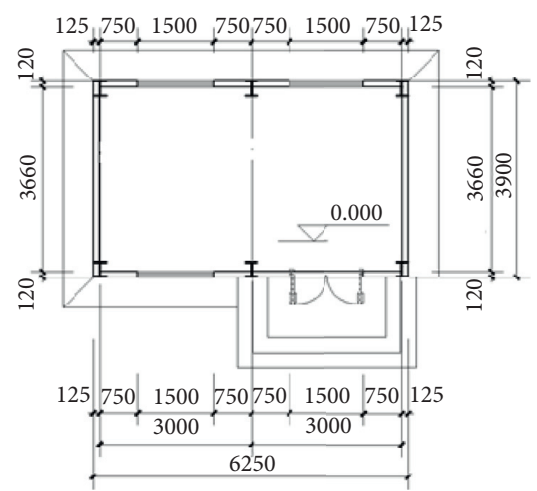

Figure 1: Testing building. (a) Front view. (b) Lateral view. (c) Installation of polystyrene board. (d) Simulation model. (e) Plan view of building.

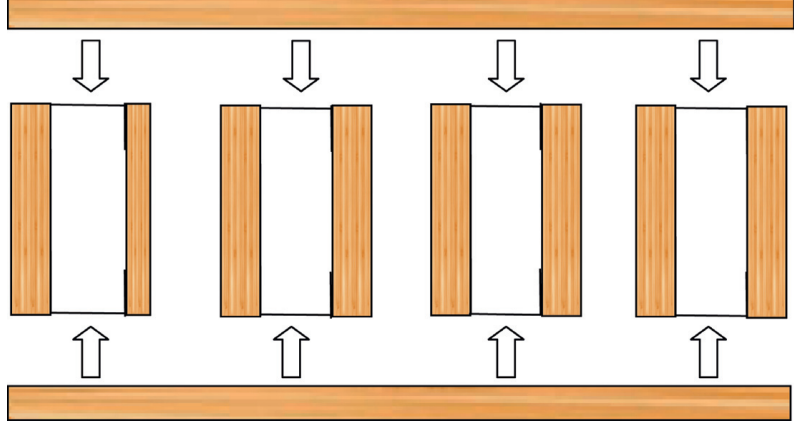

Figure 2: Structure of bamboo steel composite wall.

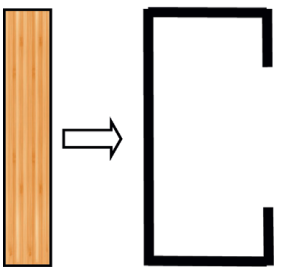

(a)

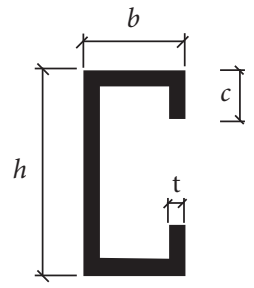

(b)
Figure 3: Bamboo steel composite skeleton. (a) Structure of the skeleton. (b) Dimension of C-type steel.

(5) The cavities between steel-bamboo composite skeletons and bamboo plywood cover panels are also filled with three layers of mineral wool (Figure 5(g)). Thus, the bamboo steel composite wall is finished (Figure 5(h)).

\section{Field Test and Simulation Analysis}

Both field test and numerical simulation were conducted to measure the thermal performance of the bamboo steel composite walls. The thermal and energy performance of the testing building were field-tested during winter.

3.1. Heat Transfer Coefficient. Heat transfer coefficient ( $K$ value for short) is an important index to assess the thermal performance of external walls. $K$ value is the amount of heat that is transferred per unit area, per time period, and per unit degree temperature difference between the internal and external of walls, which reflected how easily heat energy passes through the wall. The lower the $K$ value, the higher the heat insulation performance. Therefore, the $K$ value of bamboo steel composite walls should be experimentally measured and theoretically calculated to determine whether it satisfied the requirement of the standard [24].

3.1.1. Experimental Method. In this paper, the heat flux meter method is employed to measure the $K$ value. Heat flux meter method is one of the most commonly used methods for measuring heat transfer coefficient $[25,26]$. The test method is shown in Figure 6. A heat flux meter is arranged on the inner surface of the wall to measure the heat flux of the wall. Two temperature sensors are glued on the internal and the external surfaces of the wall to measure the temperature of the wall. Both the data of heat flux meter and temperature sensors were collected and recorded by patrol- 


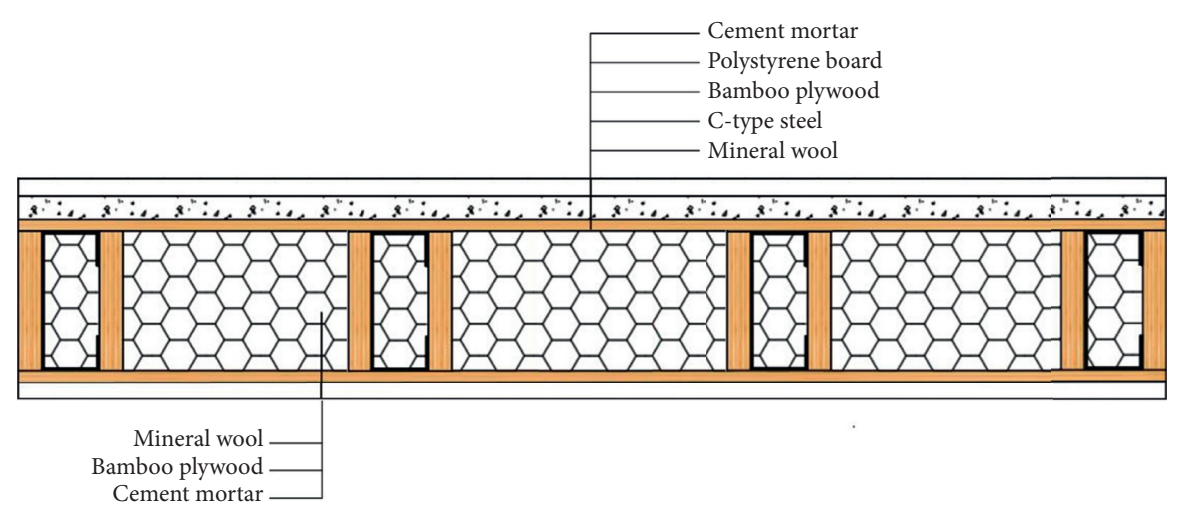

Figure 4: Construction of the composite wall.
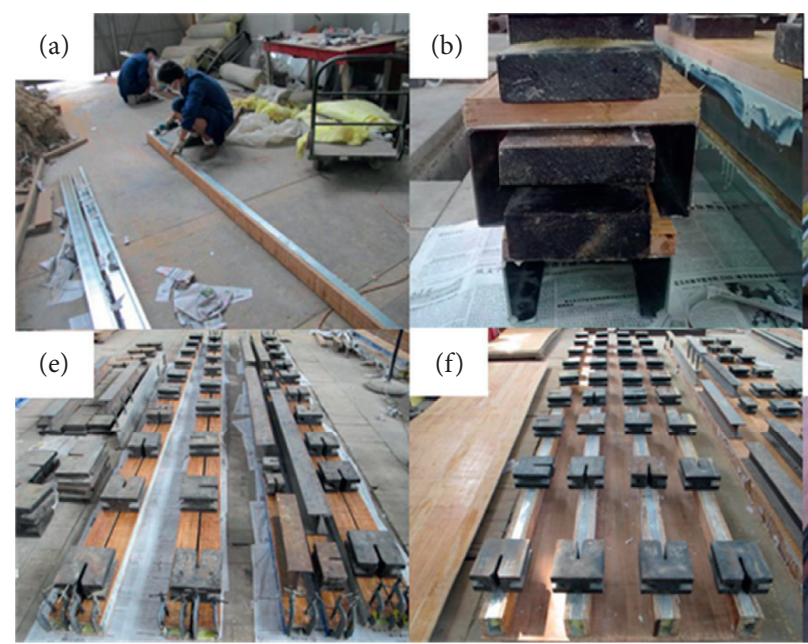

(c)
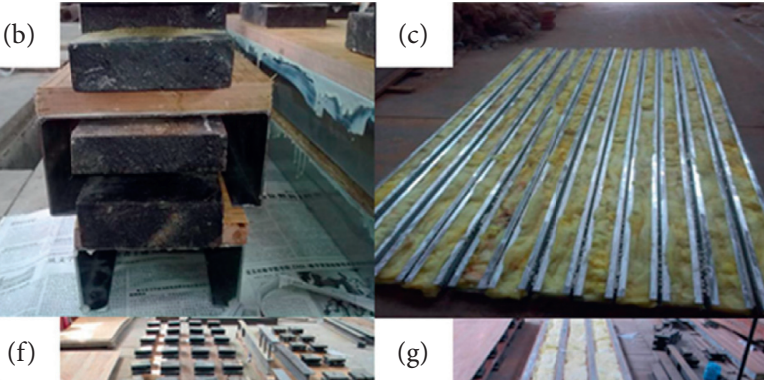

(d)

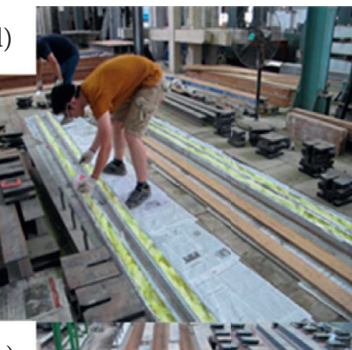

(h)

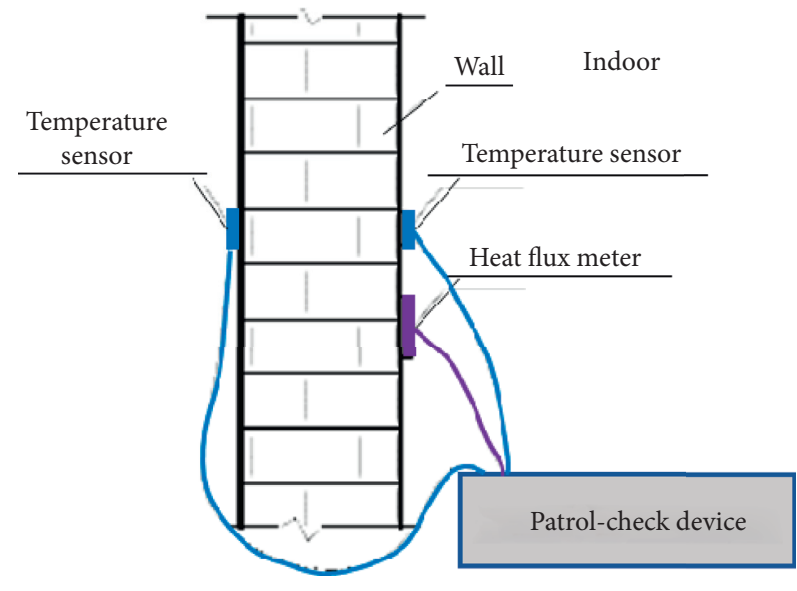

Figure 6: Heat flow meter method.

check device. The interval time of record data is set as 15 minutes in the test.

The $K$ value can be calculated as follows:

$$
K=\frac{1}{R_{\mathrm{i}}+R+R_{\mathrm{e}}},
$$

where $R_{\mathrm{i}}$ and $R_{\mathrm{e}}$ are the thermal resistance of internal and external wall, respectively. $R_{\mathrm{i}}$ and $R_{\mathrm{e}}$ here can be given as
$0.11 \mathrm{~m}^{2} \mathrm{~K} / \mathrm{w}$ and $0.04 \mathrm{~m}^{2} \mathrm{~K} / \mathrm{w}$, respectively, according to the Chinese standard [27]. $R$ is the thermal resistance of the composite wall which can be calculated through the field test. The calculation equation can be expressed as follows:

$$
R=\frac{\sum_{j=1}^{n}\left(\theta_{1 j}-\theta_{2 j}\right)}{\sum_{j=1}^{n} q_{j}} .
$$

The subscript $j$ is the time of measurement. The superscript $n$ is the total measurement time. $\theta_{1 j}$ and $\theta_{2 j}$ are the inner and outer surface temperature tested by temperature sensors. $q_{j}$ is the heat flux passed through the wall measured by heat flux meter.

3.1.2. Test Apparatus. The apparatuses including temperature sensors, heat flux meter, and patrol-check device were employed in the field test. The specification and precision of the apparatuses are introduced as follows:

Temperature sensor: the temperature sensor used in this test was a self-made T-type thermocouple, which is shown in Figure 7. This kind of T-type thermocouple was made of copper and welded with constantan wire. The temperature of the sensor ranged from $-5^{\circ} \mathrm{C}$ to $100^{\circ} \mathrm{C}$ after calibration, while the precision of the sensor 


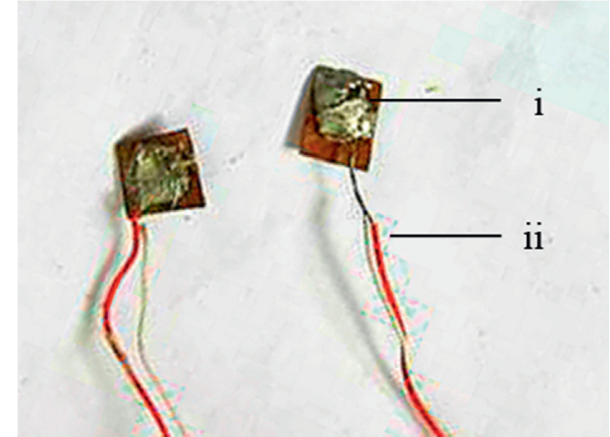

FIgURE 7: T-type thermocouple. (i) Copper; (ii) constantan wire.

was $0.1^{\circ} \mathrm{C}$ and the uncertainty of the sensor was $-0.3 \sim 0.3^{\circ} \mathrm{C}$.

Heat flux meter: the heat flux meter ranged from 0 to $2 \mathrm{kw} / \mathrm{m}^{2}$ with a precision of $5 \%$, while the size of the heat flow meter was $110 \mathrm{~mm} \times 55 \mathrm{~mm} \times 4 \mathrm{~mm}$. The heat flow meter was glued on the inner surface of the wall sealed with grease and adhesive tape. Direct sunlight should be avoided which may have effect on the test result.

Patrol-check device: a JTRG-II thermal temperature and heat flux monitor device was adopted in this paper, which could display and record both temperature and heat flux at the same time. The monitor device could record 60 routes of temperature data and 30 routes of heat flow data at the same time.

3.1.3. Arrangement of Monitoring Point. According to the Chinese standard $[25,26]$, to measure heat transfer coefficient, the arrangement of monitoring point is essential in the field test. The monitoring point should be arranged near the center of the wall where it is far away from the columns, windows, corners, beams, and cracks. Considering the particularity of the composite wall structure, the center of the east wall of the test building is chosen to arrange the monitoring point, where neither the composite skeletons nor the location of the connection is located. The locations of the monitoring points are shown in Figure 8.

3.1.4. Requirement of Field Test. The field test complied with Chinese standards [25]. The bamboo steel composite walls belong to lightweight building envelope, and the field test of $K$ value should be carried out during the night. Thus, the data used to calculate the $K$ value in this paper were collected from 20:00 to 6:00. During the measurement, the temperature difference between inside and outside should be more than $10^{\circ} \mathrm{C}$ to make sure that heat energy passed through the wall steadily. The steady state of heat transfer cannot be reached until the deviation of calculated daily average $K$ value between 2 continuous measurements is less than $5 \%$. The field test of $K$ value can be finished after 4 continuous measurements during the steady state of heat transfer. The measured $K$ value of the composite walls can be determined by the average value of calculated daily average $K$ value.
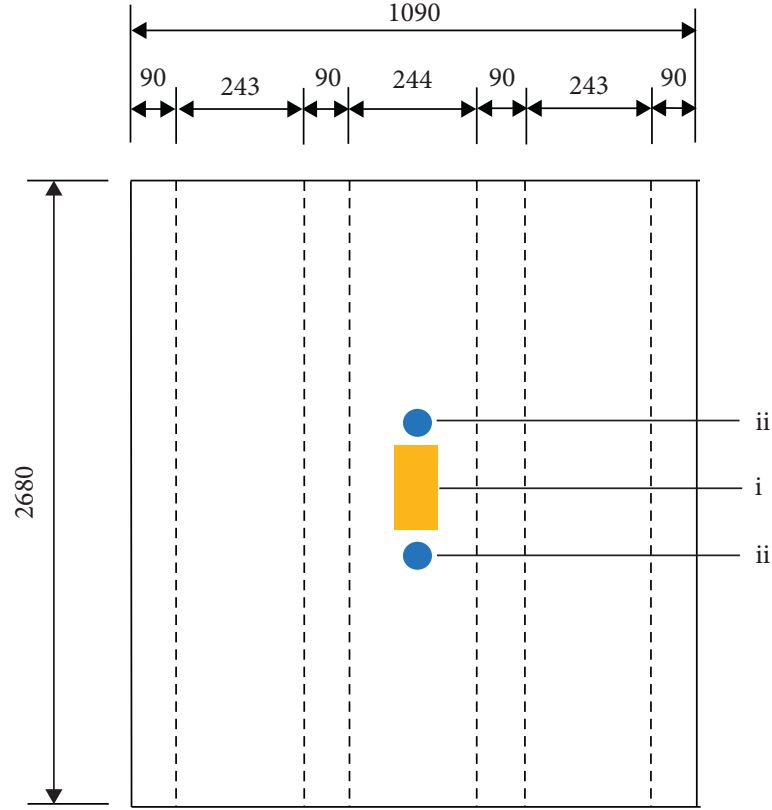

FIGURE 8: Arrangement of monitoring points on the east wall. (i) Heat flux meter; (ii) T-type thermocouple. Note: the dotted line is the location of the composite skeletons.

3.2. Energy Performance. An air condition for heating was installed in the testing building. The COP (coefficient of performance) of the air condition was 2.89. During the field test of $K$ value, the air condition was kept on and the temperature was set at $18^{\circ} \mathrm{C}$ to ensure the temperature difference between indoor and outdoor was more than $10^{\circ} \mathrm{C}$. An electric meter was installed to observe and record the heating energy consumption of the testing building. The measured energy consumption would be used to verify the validity of the simulation model for further investigation.

3.3. Computer Simulation. The testing building was simulated by the software EnergyPlus. It is an open-source, whole building energy modelling engine that can simulate both energy consumption (such as heating and cooling) and water usage in buildings.

The energy performance of the composite wall was simulated and compared with reinforced concrete wall, a typical wall structure commonly used in China. The construction of these two types of walls is listed in Table 1 (denoted as wall1 and wall2, respectively). The design of wall 2 was required to meet the thermal performance of the standard (no more than $1.5 \mathrm{~W} / \mathrm{m}^{2} \mathrm{~K}$ ) [24]. The simulation between wall1 and wall 2 was based on the same building model except the materials of wall and roof. The building model with wall1 adopted bamboo steel composite roof with an insulation layer (as shown in Table 1), while the other building model with wall 2 employed reinforced concrete roof. Both building models have the same reinforced concrete floor.

Four typical cities in different climate regions in China were selected to analyse the energy performance of these two wall structures including hot summer/warm winter region 
TABLE 1: Thermal properties of building materials.

\begin{tabular}{|c|c|c|c|c|c|}
\hline Building members & Materials & $\delta(\mathrm{m})$ & $\lambda(\mathrm{W} / \mathrm{mK})$ & $c(\mathrm{~J} / \mathrm{kgK})$ & $\rho\left(\mathrm{kg} / \mathrm{m}^{3}\right)$ \\
\hline \multirow{8}{*}{ Bamboo steel composite wall (wall1) } & Cement mortar & 0.015 & 0.93 & 1050 & 1800 \\
\hline & Polystyrene board & 0.02 & 0.042 & 1500 & 20 \\
\hline & Bamboo plywood & 0.01 & 0.17 & 2510 & 600 \\
\hline & C-type steel & 0.001 & 58.2 & 480 & 7800 \\
\hline & Mineral wool & 0.098 & 0.05 & 840 & 32 \\
\hline & C-type steel & 0.001 & 58.2 & 480 & 7800 \\
\hline & Bamboo plywood & 0.01 & 0.17 & 2510 & 600 \\
\hline & Cement mortar & 0.015 & 0.93 & 1050 & 1800 \\
\hline \multirow{4}{*}{ Reinforced concrete wall (wall2) } & Cement mortar & 0.015 & 0.93 & 1050 & 1800 \\
\hline & Polystyrene board & 0.02 & 0.042 & 1500 & 20 \\
\hline & Reinforced concrete & 0.24 & 1.74 & 1094 & 1700 \\
\hline & Cement mortar & 0.015 & 0.93 & 1050 & 1800 \\
\hline \multirow{8}{*}{ Roof1 for building with wall1 } & Fine aggregate concrete & 0.03 & 1.51 & 920 & 2400 \\
\hline & Polystyrene board & 0.02 & 0.042 & 1500 & 20 \\
\hline & Bamboo plywood & 0.01 & 0.17 & 2510 & 600 \\
\hline & C-type steel & 0.001 & 58.2 & 480 & 7800 \\
\hline & Mineral wool & 0.098 & 0.05 & 840 & 32 \\
\hline & C-type steel & 0.001 & 58.2 & 480 & 7800 \\
\hline & Bamboo plywood & 0.01 & 0.17 & 2510 & 600 \\
\hline & Cement mortar & 0.03 & 0.93 & 1050 & 1800 \\
\hline \multirow{4}{*}{ Roof 2 for buildings with wall 2} & Fine aggregate concrete & 0.03 & 1.51 & 920 & 2400 \\
\hline & Polystyrene board & 0.02 & 0.042 & 1500 & 20 \\
\hline & Reinforced concrete & 0.12 & 1.74 & 920 & 2500 \\
\hline & Cement mortar & 0.03 & 0.93 & 1050 & 1800 \\
\hline \multirow{2}{*}{ Floor } & Cement mortar & 0.03 & 0.93 & 1050 & 1800 \\
\hline & Reinforced concrete & 0.12 & 1.74 & 920 & 2500 \\
\hline
\end{tabular}

Note. $\delta$ is the thickness; $\lambda$ is the thermal conductivity; $c$ is the thermal capacity; $\rho$ is the density.

(Guangzhou), hot summer/cold winter region (Shanghai), cold region (Beijing), and severe cold region (Harbin).

The simulation setting followed the testing building and the setting items are listed in Table 2. The operation schedule of air condition was assumed to run throughout the year to meet the indoor temperature setting. The total power density of miscellaneous loads (including lighting systems and occupants) was set to $4.3 \mathrm{~W} / \mathrm{m}^{2}$. All these thermal settings complied with the design standard in China [24].

\section{Results and Discussion}

\subsection{Heat Transfer Coefficient}

4.1.1. Test Results. The test of $K$ value of the composite wall was carried out during 5 typical winter days from 2016/1/26 to $2016 / 1 / 30$. The average internal and external surface temperature of the composite wall are shown in Figure 9(a). The temperature curves showed that the internal surface temperature of the wall increased obviously with the increase of time. After about 8 hours, it reached the setting temperature of the air condition, and the temperature was kept at about $18^{\circ} \mathrm{C}$ with a little fluctuation, which indicated that the air conditioner could meet the demand for the indoor continuous heating. The external surface of the wall changed slightly due to the cloudy weather during the measurement period.

Figure 9(b) exhibits the heat flux rate of the test wall during the measurement. The heat flux rate is high at the beginning of the test due to unstable transfer of heat flux. Then, the heat flux rate dropped to about $5 \mathrm{~W} / \mathrm{m}^{2}$ after 9 hours and fluctuated with the temperature difference between the internal and external wall.

The calculated results of $K$ value during the field test period are exhibited in Figure 9 (c); the $K$ value constantly decreased with the increase of indoor temperature in the beginning and tended to be stable after about 9 hours, which indicated that the heat transfer of the wall reached the steady state. The $K$ value kept approximately constant with a small fluctuation during the night at a steady state. Thus, the data measured during the night from 20:00 to 6:00 was used to calculate the daily average $K$ value. The differences between daily average $K$ values are listed in Table 3 . From Table 3, we can find that the difference of the daily average $K$ value compared to it of the previous day was less than $5 \%$ in the last 3 measurements, so the measured $K$ value is the average of the last 4 daily average $K$ values and the test result is $0.447 \mathrm{~W} / \mathrm{m}^{2} \mathrm{~K}$.

4.1.2. Theoretical Calculation Value. As is described in Section 2.1, the bamboo steel composite walls are made of multi-layer materials, which is shown in Figure 4.

According to the design code [27], the thermal resistance of a single material can be defined as $R_{i}=\delta_{i} / \lambda_{i}$. Thermal resistance of multi-layer enclosure structure is calculated as $R=R_{1}+R_{2}+R_{3}+\cdots+R_{n}$. The thickness and thermal conductivity of each material are shown in Table 4 . The mineral 
TABLE 2: Setting items of building models.

\begin{tabular}{lcc}
\hline Setting items & \multicolumn{2}{c}{ Value } \\
\hline $\begin{array}{l}\text { Purpose } \\
\text { Location }\end{array}$ & Verification & Energy performance \\
Area of building & Ningbo & Harbin, Beijing, Shanghai, Guangzhou \\
Building envelope & $24 \mathrm{~m}^{2}$ & Wall1 + Roof1 + Floor, \\
& Wall1 + Roof1 + Floor & Wall $2+$ Roof $2+$ Floor \\
Window-to-wall ratio & North wall: 0.24 , south wall: 0.31 , west and east wall: 0 \\
& Temperature: $18^{\circ} \mathrm{C}$ & Temperature: $16^{\circ} \mathrm{C}$ (winter), \\
Air condition & Run time: $2016 / 1 / 26-2016 / 1 / 30$ & $26^{\circ} \mathrm{C}($ summer) \\
Weather condition & Measured & Run time: whole year \\
Miscellaneous loads & 0 & Typical meteorological year \\
\end{tabular}

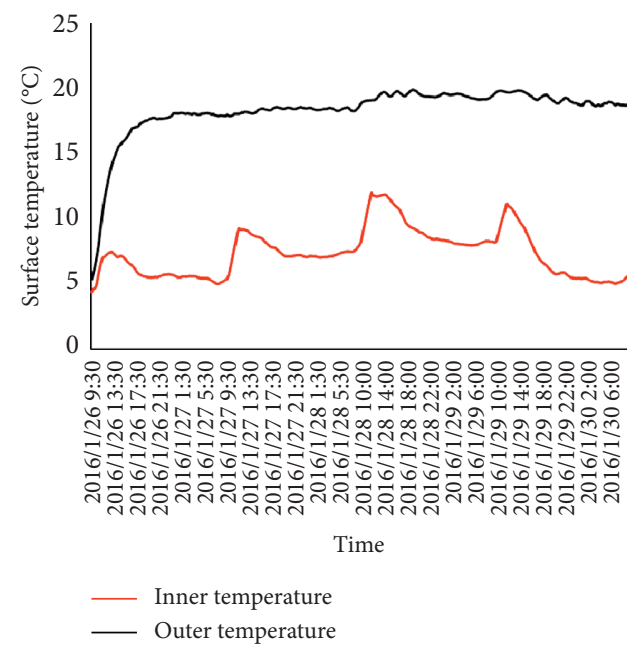

(a)

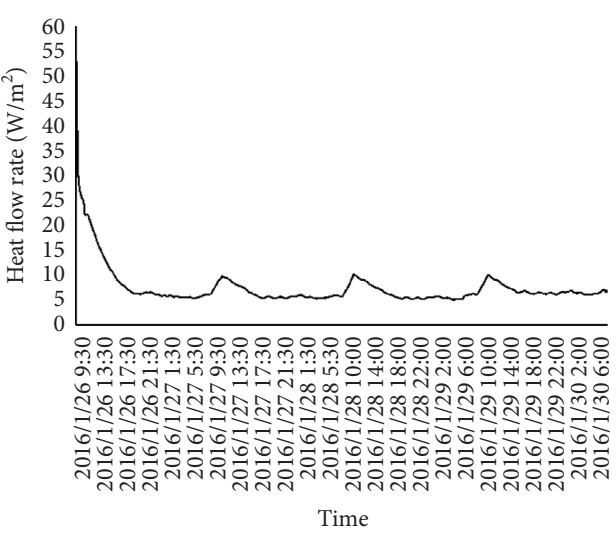

(b)

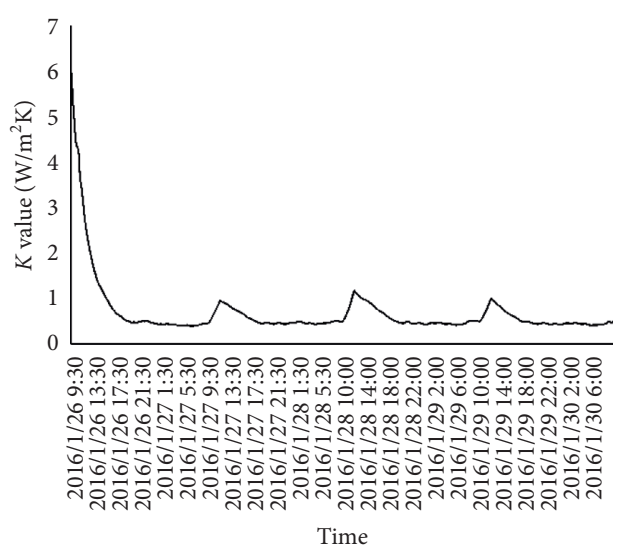

(c)

Figure 9: Field test results of $K$ value during winter. (a) Average temperature of inner and outer surface wall. (b) Test result of heat flux rate. (c) Calculated $K$ value during the measurements.

wool and polystyrene board employed as heat insulating material of wall will sink during the service stage, so the thermal conductivity should be modified. The correction factor of mineral wool and polystyrene board is 1.2 and 1.1, respectively, which is shown in Table 4 .

The calculative processes of the thermal resistance of bamboo steel composite wall are listed in Table 4 . The total thermal resistance of composite wall is $2.216 \mathrm{~m}^{2} \mathrm{~K} / \mathrm{W}$ according to the table. Thus, the $K$ value of the composite wall can be calculated by equation (2) and the theoretical result is $0.423 \mathrm{~W} / \mathrm{m}^{2} \mathrm{~K}$.

4.1.3. Comparison of $K$ Value. The theoretical calculation and measured $K$ values of the bamboo steel composite wall are listed, respectively, in Table 5. It can be found that the 
TABLE 3: Comparison of the daily average $K$ values.

\begin{tabular}{|c|c|c|c|c|c|}
\hline Date & $1 / 26$ & $1 / 27$ & $1 / 28$ & $1 / 29$ & $1 / 30$ \\
\hline Daily average $\left(\mathrm{W} / \mathrm{m}^{2} \mathrm{~K}\right)$ & 0.485 & 0.443 & 0.460 & 0.443 & 0.440 \\
\hline Difference (\%) & - & 8.82 & 3.99 & 3.74 & 0.66 \\
\hline Measurement $K$ value $\left(\mathrm{W} / \mathrm{m}^{2} \mathrm{~K}\right)$ & & & 0.447 & & \\
\hline
\end{tabular}

TABLE 4: Calculative processes of thermal resistance.

\begin{tabular}{|c|c|c|c|c|c|}
\hline Building member & Materials & $\delta(\mathrm{m})$ & $\lambda(\mathrm{W} / \mathrm{mK})$ & Correction factor & $R\left(\mathrm{~m}^{2} \mathrm{~K} / \mathrm{W}\right)$ \\
\hline \multirow{8}{*}{ Bamboo steel composite wall (wall1) } & Cement mortar & 0.015 & 0.93 & - & 0.016 \\
\hline & Polystyrene board & 0.02 & 0.042 & 1.1 & 0.433 \\
\hline & Bamboo plywood & 0.01 & 0.17 & - & 0.059 \\
\hline & C-type steel & 0.001 & 58.2 & - & 0.000 \\
\hline & Mineral wool & 0.098 & 0.05 & 1.2 & 1.633 \\
\hline & C-type steel & 0.001 & 58.2 & - & 0.000 \\
\hline & Bamboo plywood & 0.01 & 0.17 & - & 0.059 \\
\hline & Cement mortar & 0.015 & 0.93 & - & 0.016 \\
\hline Total & & & & & 2.216 \\
\hline
\end{tabular}

Note. The thermal resistance of C-type steel can be neglected due to the thin thickness and high thermal conductivity.

TABLE 5: Comparison among theoretical value and measured value and standard limit value.

\begin{tabular}{lc}
\hline Items & $K$ value $\left(\mathrm{W} / \mathrm{m}^{2} \mathrm{~K}\right)$ \\
\hline Measurement value & 0.447 \\
Theoretical calculation value & 0.423 \\
The standard limit value $[24]$ & 1.5 \\
\hline
\end{tabular}

calculation value matched well with the measurement value and the relative error is about $5 \%$.

The comparison results show that the heat flux meter method is suitable for the field test of $K$ value. Both the measurement value and theoretical calculation value are less than the limit value which indicates that the composite walls have an excellent thermal performance and can satisfy the requirement of the standard.

\subsection{Energy Performance}

4.2.1. Verification of the Simulation Model. As is described in Section 3.2, the air condition in testing building was adopted to keep the indoor temperature. The energy consumption of building was recorded by the electric meter. The reads of the electric meter are listed in Table 6, and the energy consumption based on measurement is $11.8 \mathrm{kWh}$ according to Table 6. Then, the simulation model based on the testing building was conducted to verify the validity of the model. The simulated result was $10.52 \mathrm{kWh}$, which is a little lower than the test result by $10.8 \%$. Because the heating performance (COP) of the air condition changes with outdoor conditions, there is an acceptable difference between simulated and measured heating energy consumption. Therefore, the proposed simulation model to analyse energy performance of the composite wall in different climate regions is verified.

4.2.2. Parametric Analysis. The annual energy consumption of the two walls in different climate regions are illustrated in Figure 10.
Table 6: Reads of the electric meter.

\begin{tabular}{lc}
\hline Items & Value $(\mathrm{kWh})$ \\
\hline Initial reading of electric meter & 35.4 \\
Final reading of electric meter & 47.2 \\
Energy consumption & 11.8 \\
\hline
\end{tabular}

According to the simulation result in Figure 10, the energy consumption in different climate regions was different. Guangzhou had the lowest energy consumption among the four typical cities. That is because the average annual temperature is close to the setting temperature of air condition. Buildings in Shanghai consumed both heating and cooling energy due to the hot summer and cold winter climate feature, but the total consumption is lower than Beijing and Harbin. Both Beijing and Harbin consumed heating energy while demanding little cooling energy.

Due to the lower $K$ value, Wall1 had the better heating energy performance than wall2. The heating energy consumption of wall 1 was lower than that of wall 2 by $30.18 \%$, $37.48 \%, 33.3 \%$, and $32.03 \%$ in the four cities (namely, Guangzhou, Shanghai, Beijing, and Harbin), respectively.

For the cooling energy demand in Guangzhou, Shanghai, and Beijing, wall1 had the better performance than wall2 with the improvement of $36.22 \%, 37.57 \%$, and $28.36 \%$, respectively. This is due to the fact that wall1 with lower $K$ value can prevent heat energy from passing through the wall more effectively. However, the cooling energy consumption of wall1 is larger than that of wall2 in Harbin. That is because the typical summer temperature of Harbin used in the simulation merely exceeded $26^{\circ} \mathrm{C}$; the heat energy was generated by the equipment in the room. The heat energy cannot be dissipated easily due to the lower $K$ value of Wall1. Thus, the cooling energy was demanded more in wall1.

For the total energy demand, the consumption of wall1 was lower than that of wall 2 by $35.93 \%, 37.51 \%, 32.75 \%$, and $31.71 \%$, respectively, which showed that the bamboo steel composite walls had the potential to be employed as building envelope in China. 


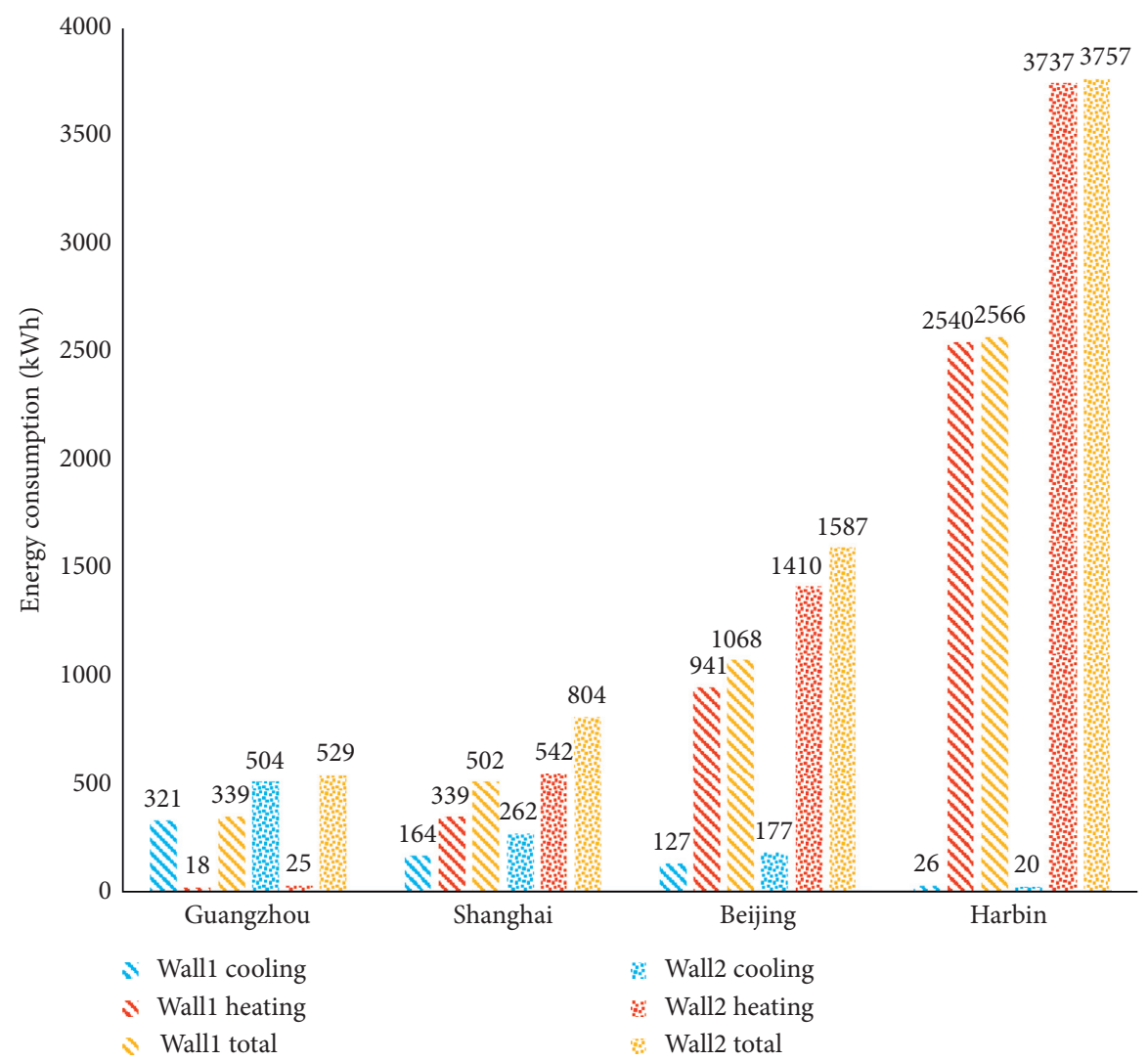

Figure 10: Comparison of annual energy consumption of the two walls in four cities.

\section{Conclusion}

In this paper, the thermal performance of a novel bamboo steel composite wall was experimentally investigated and numerically simulated. The key conclusions based on the analysis are summarized as follows:

(1) In the field test, the heat transfer method was employed to measure the heat transfer coefficient $(K$ value) of the wall. The measurement value was less than the limit value, which indicated that the composite walls had an excellent thermal performance and could satisfy the requirement of the standard.

(2) A theoretical formula for $K$ value of the bamboo steel composite wall was presented and the calculation value matched well with the measurement value.

(3) The validity of the simulation model was verified through the field test; then, the proposed model was adopted to analyse the energy performance of the composite wall. The simulation result indicated that the composite walls had better energy performance compared with reinforced concrete wall and could be employed as building envelope in China.

\section{Data Availability}

The data used to support the findings of this study are available from the corresponding author upon request.

\section{Conflicts of Interest}

The authors declare that there are no conflicts of interest regarding the publication of this paper.

\section{Acknowledgments}

The authors gratefully acknowledge the financial support provided by the National Key R\&D Program of China (2019YFD1101002), the National Natural Science Foundation of China (NSFC) (51678310 and 51978345), and Ningbo Science and Technology Project (202002N3090).

\section{References}

[1] K. D. Flander and R. Rovers, "One laminated bamboo-frame house per hectare per year," Construction and Building $\mathrm{Ma}$ terials, vol. 23, no. 1, pp. 210-218, 2009.

[2] J. Li, "Towards a low-carbon future in China's building sector-a review of energy and climate models forecast," Energy Policy, vol. 36, no. 5, pp. 1736-1747, 2008.

[3] P. van der Lugt, A. A. J. F. van den Dobbelsteen, and J. J. A. Janssen, "An environmental, economic and practical assessment of bamboo as a building material for supporting structures," Construction and Building Materials, vol. 20, no. 9, pp. 648-656, 2006.

[4] X. Sun, M. He, and Z. Li, "Novel engineered wood and bamboo composites for structural applications: state-of-art of manufacturing technology and mechanical performance evaluation," Construction and Building Materials, vol. 249, Article ID 118751, 2020. 
[5] D. U. Shah, M. C. D. Bock, H. Mulligan, and M. H. Ramage, "Thermal conductivity of engineered bamboo composites," Journal of Materials Science, vol. 51, no. 6, pp. 2991-3002, 2016.

[6] H. Takagi, S. Kako, K. Kusano, and A. Ousaka, "Thermal conductivity of PLA-bamboo fiber composites," Advanced Composite Materials, vol. 16, no. 4, pp. 377-384, 2007.

[7] L. L. Xiang, N. P. Li, Z. Chen, and X. W. Chen, "Research of thermal and moisture transport within compound bamboo wall with different moisture content," Key Engineering $M a-$ terials, vol. 517, pp. 887-891, 2012.

[8] F. F. Risnandar and S. Wonorahardjo, "Thermal performance of plastered bamboo-wall," KnE Social Sciences, vol. 3, no. 21, pp. 284-296, 2019.

[9] J. S. Wang, C. Demartino, Y. Xiao, and Y. Y. Li, “Thermal insulation performance of bamboo- and wood-based shear walls in light-frame buildings," Energy and Buildings, vol. 168, pp. 167-179, 2018.

[10] A. Zhou and Y. Bian, "Experimental study on the flexural performance of parallel strand bamboo beams," The Scientific World Journal, vol. 2014, Article ID 181627, 6 pages, 2014.

[11] J. Lei, B. Chen, and P. Yuan, "Experimental study on flexural properties of side-pressure laminated bamboo beams," Advances in Civil Engineering, vol. 2020, Article ID 5629635, 10 pages, 2020.

[12] V. De Luca and C. Marano, "Prestressed glulam timbers reinforced with steel bars," Construction and Building Materials, vol. 30, pp. 206-217, 2012.

[13] Y. Wei, M. Zhou, and D. Chen, "Flexural behaviour of glulam bamboo beams reinforced with near-surface mounted steel bars," Materials Research Innovations, vol. 19, no. 1, pp. S1-S103, 2015.

[14] Y. Wei, X. Ji, M. Duan, and G. Li, "Flexural performance of bamboo scrimber beams strengthened with fiber-reinforced polymer," Construction and Building Materials, vol. 142, pp. 66-82, 2017.

[15] Y.-F. Li, Y.-M. Xie, and M.-J. Tsai, "Enhancement of the flexural performance of retrofitted wood beams using CFRP composite sheets," Construction and Building Materials, vol. 23, no. 1, pp. 411-422, 2009.

[16] Y. Nadir, P. Nagarajan, M. Ameen, and M. Arif, "Flexural stiffness and strength enhancement of horizontally glued laminated wood beams with GFRP and CFRP composite sheets," Construction and Building Materials, vol. 112, pp. 547-555, 2016.

[17] H. Fang, X. Xu, W. Liu et al., "Flexural behavior of composite concrete slabs reinforced by FRP grid facesheets," Composites Part B: Engineering, vol. 92, pp. 46-62, 2016.

[18] Q. Lv, W. Wang, and Y. Liu, "Flexural performance of crosslaminated bamboo (CLB) slabs and CFRP grid composite CLB slabs," Advances in Civil Engineering, vol. 2019, Article ID 6980782, 17 pages, 2019.

[19] T. Liu, Y. Li, K. Xu et al., "Research on mechanical performance of steel-bamboo composite box short column," Industrial Construction, vol. 46, no. 1, pp. 25-29, 2016.

[20] Y. Li, H. Shen, W. Shan et al., "Experimental study on shear behavior of I-shaped section bamboo-steel composite beams," Journal of Building Structures, vol. 32, no. 7, pp. 80-86, 2011.

[21] Y. Li, W. Shan, Z. Huang et al., "Experimental study on mechanical behavior of profiled steel sheet-bamboo plywood composite slabs," Journal of Building Structures, vol. 29, no. 1, pp. 96-102, 2008.
[22] Y. Li, H. Shen, W. Shan, and T. Han, "Flexural behavior of lightweight bamboo-steel composite slabs," Thin-Walled Structures, vol. 53, pp. 83-90, 2012.

[23] Y. Li, J. Guo, T. Jiang et al., "Experimental study on seismic behavior of cold-formed Thin-walled C steel-bamboo plywood composite walls," Journal of Shenyang Jianzhu University (Natural Science), vol. 29, no. 6, pp. 969-976, 2013.

[24] Engineering Construction Standard of Zhejiang Province, Design Standard for Energy Efficiency of Residential Buildings (DB33/1015-2015), China Planning Press, Beijing, China, 2015.

[25] China National Standard, Test Standard for Overall Heat Transfer Coefficient of Building Envelope and Heat Supply for Space Heating (GB/T23483-2009), Standards Press of China, Beijing, China, 2009.

[26] China Industrial Standard, Standard for Energy Efficiency Test of Residential Buildings (JGJ/T 132-2009), China Architecture \& Building Press, Beijing, China, 2010.

[27] China National Standard, Code for Thermal Design of Civil Building (GB 50176-2016), China Architecture \& Building Press, Beijing, China, 2016. 